\title{
A dynamic model to illustrate the development of an interregional energy household to a sustainable status
}

\author{
Florian Hug, Hans-Peter Bader, Ruth Scheidegger, Peter Baccini
}

Abstract Approximately $90 \%$ of worldwide energy consumption is based on non-renewable forms of energy. For well-known reasons, there is a necessity to change the present energy concept. A dynamic model, based on the material flux analysis method is used to simulate a possible development of the interregional energy household for the Swiss highland and lowland. The aim is an energy supply based mostly on the regional potentials of resources. Three scenarios answer questions about limiting aspects of implementation, which are responsible for the time necessary to reach a target status. The results show that the regions can complementarily manage their energy household. At least two generations are necessary to reach the target status. The limits of implementation are the production and installation of new energy systems and not the energy demand to build them up.

$\begin{array}{ll}\text { Abbreviations } \\ C H & \text { Switzerland } \\ D S S & \text { Degree of self-sufficiency } \\ G W h & \text { Gigawatt hour } \\ H L & \text { Highland } \\ k W h & \text { Kilowatt hour } \\ L L & \text { Lowland } \\ M F A & \text { Material flux analysis } \\ T W h & \text { Terawatt hour }\end{array}$

\section{Introduction}

Today, approximately $90 \%$ of worldwide energy consumption is based on non-renewable forms of energy,

Received: 20 February 2003 / Accepted: 2 June 2003

Published online: 25 July 2003

(c) Springer-Verlag 2003

F. Hug, P. Baccini

Department of Resource and Waste Management, Swiss Federal Institute of Technology,

ETH-Hönggerberg, 8093 Zürich, Switzerland

H.-P. Bader ( $\square)$, R. Scheidegger

Department of Resource and Waste Management (S+E),

Swiss Federal Institute for Environmental Science and Technology

(EAWAG), P.O. 611, Dübendorf, Switzerland

E-mail: bader@eawag.ch

Tel.: ++411 8235501

Fax: ++411 8235226

We would like to thank M. Bader for helpful discussions and S. Hug-Iten and F. Pfister for carefully reading the manuscript. mostly mineral oil (OECD/IEA 2000). For several reasons there is a necessity to change the present concept of energy use. The burning of fossil fuels contributes to the greenhouse effect, fossil resources are limited and the replenishment is approximately one million times slower than the actual rate of usage. The prognoses for the future energy demand show a strong increase in energy use due to the expected additional requirement per capita and the increase of the world population to approximately 8 billion people in 2025 (OECD/IEA 2000). In the context of fairness of worldwide distribution, climate change risks, atmospheric pollution and regional supply security, every region is required by the Rio agenda 21 (Keating 1998) to consider on a long-term scale how to improve its own energy management in a sustainable way (e.g., replacing nonrenewable resources by renewable resources, increasing resource efficiency, increasing the degree of regional selfsufficiency). Therefore, the question of opportunities for neighbouring regions with different resource potentials, e.g. highland and lowland regions to find a win-win situation in energy management becomes relevant. The present study is based on the hypothesis that two regions with different energy resource potentials can complementarily manage their energy household. The notion of energy household includes the supply, use and dissipation of all forms of non-renewable energy such as mineral oil, gas, coal and nuclear power as well as all forms of renewable solar energy and geothermal heat for the region considered.

Various studies exist on the mass, energy and substance household of lowland and highland regions. Mass and substance household are defined in a similar way to energy household. The energy and substance household of lowland urban regions is illustrated in Baccini and Brunner (1991), Baccini and Bader (1996), Müller (1998), Redle (1999) and Faist (2000). Binder et al. (2001) investigated a dynamic approach on a regional scale to manage durables in a region in Columbia. The same approach is used in Zeltner et al. (1999) to describe a sustainable metal management in the U.S.A. A similar approach has been chosen by Johnstone (2001a, 2001b) to estimate energy and mass flows of housing. All these studies focus on regional resource management but not specially on energy and interregional aspects. In Hug and Baccini (2002) the interregional household for energy and nourishment is presented as a steady-state model. Real (1998) exemplified the large-scale introduction of renewable electricity systems with a dynamic model. As Real (1998) showed, longterm modelling (30 to 60 years) of energy household development from a status quo to a target status in the 
future requires dynamic modelling. For the discussion of the above mentioned opportunities for the co-operation of two regions to change their energy household a combination of the dynamic approach used in Real (1998), Binder et al. (2001) and Zeltner et al. (1999) with the method for interregional modelling presented in Hug and Baccini (2002) has been used. The notion of dynamic modelling is used here for an approach where all variables (energy fluxes and stocks) are time dependent and interrelated by dynamical system equations. The main questions to be answered in this paper are the following:

(i) How can the regional and interregional energy management of two regions and their global hinterland be modelled dynamically over several generations?

(ii) How do energy and material flows change as a function of time when the system is transformed from the present state to a more sustainable state?

(iii) How much time is necessary to reach a target state in a system-compatible way and which aspects of manufacturing and installation capacity, and endenergy demand for manufacturing thereby limit the speed of this development? "System compatible" means in this context to guarantee all necessary activities for daily life during the whole time period considered.

Choosing the target state is part of the scenarios. The target state for all scenarios assumes a large implementation of renewable energy systems and changes in energy consumption levels and habits.

The model is restricted to technical properties on a regional level and does not include economic factors. It is not a goal of the present study either to make prognoses or to give practical advice on the implementation of renewable energy systems. Instead, the goal is to show the regional possibilities and potentials for energy on the way to a more sustainable regional and interregional energy household.

\section{Study area}

As the study area two neighbouring regions with different resource potentials for energy have been chosen. The Swiss highland (HL) and the neighbouring Swiss lowland (LL) represent such a two-region system, forming Switzerland (CH) with an area of about $41,000 \mathrm{~km}^{2}$. The HL covers up two thirds of the area $\left(28,000 \mathrm{~km}^{2}\right)$ and the LL the rest $\left(13,000 \mathrm{~km}^{2}\right)$. In this study the borderline between the HL and the LL was chosen based on the Swiss law for subsidising the highlands (SR 901.1 1997). Only one fourth (1.7 million) of the total population lives in the HL, whereas 5.3 million people live in the LL. The population density is, therefore, about seven times lower in the HL
( 60 people per $\mathrm{km}^{2}$ ) than in the LL (400 people per $\left.\mathrm{km}^{2}\right)$. A larger total area per inhabitant, increasing precipitation with increasing altitude and a higher gravity potential are the reasons for a greater potential of hydropower in total or per inhabitant in the HL. Similar considerations apply to solar electricity and solar heat due to increasing solar irradiation with increasing altitude.

The most important characteristics of the energy household in the status quo can be found in Table 1 (data from Hug 2002). Both regions have to import energy to operate their systems. The HL produces end-energy of about $28 \mathrm{TWh}$ /year of which $80 \%$ is hydroelectric power. The high amount of hydroelectric power in Switzerland results from the fact that about $80 \%$ of the freshwater streams are used hydro-electrically (Truffer et al. 2001). Hydro-electricity is the main reason for the actual much higher regional energy supply of the HL (HL: 28 TWh/year, LL: 11 TWh/year). The ratio between regional supply to the overall regional demand is called the degree of self-sufficiency (DSS). This indicator can easily show if a region is lacking a certain good or if there is a net surplus. The DSS is used in this study to evaluate the opportunities of two regions to manage complementarily their energy household. Evaluating the DSS shows that in the status quo the HL can cover about one half of its total demand (53\%) while the LL covers only $6 \%$ respectively. Switzerland as a whole has a DSS of $16 \%$. This value corresponds also to the amount of renewable energies because Switzerland has no fossil energy sources of its own. Today, the Swiss DSS of $16 \%$ is of the same order of magnitude as the world degree of renewable energies of approximately $10 \%$ (calculated with data presented in the Introduction). For more regional characterisation of the study area; see Hug and Baccini (2002) and Hug (2002).

\section{Method}

Dynamical material flux analysis (MFA) is used to describe and simulate the regional resource management. The method is described in detail in Baccini and Bader (1996) and has been successfully applied in different fields (Müller 1998, Real 1998, Redle 1999, Zeltner et al. 1999, Faist 2000, Binder et al. 2001, Hug and Baccini 2002) and ongoing work. The method contains four steps, which are briefly explained. The first step is the system analysis in which system border processes and goods relevant for the system considered have to be defined. A second step is the mathematical description of the chosen system. The calibration follows in a third step. Finally, the last step includes simulations and uncertainty analysis.

\section{System analysis}

The first step, system analysis, has to define the system that is best suited to answer the key questions of the Introduction.

Table 1. Total regional end energy supply and consumption in TWh per year and the degree of self-sufficiency (DSS) in percent for the status quo in the highland (HL), the lowland (LL) and Switzerland (CH), calculated with data from Hug (2002)

\begin{tabular}{|c|c|c|c|}
\hline & $\mathrm{HL}$ & LL & $\mathrm{CH}$ \\
\hline Total regional energy consumption for the status quo (TWh/year) & 54 & 182 & 236 \\
\hline
\end{tabular}


This step includes the definition of the system border, all the relevant processes and the interactions between and with the other region and the global hinterland.

The overall system consists of two interacting subsystems with identical processes (Fig. 1). The upper subsystem represents the HL and the lower subsystem the LL.

Each regional subsystem contains a process of energy industry, a process of energy consumption and nine internal energy supply processes, combined with 30 energy flows. These nine supply processes are photovoltaic, solar heat, hydropower, combustion of wood, waste incineration, environmental heat, deep geothermal heat, nuclear power and gas- or oil-fired co-generation.

The powers of the energy supply processes are given by the number of installed specific power plant units. These specific units are $1 \mathrm{~m}^{2}$ for photovoltaic energy and solar heat. For all other supply processes a specific unit corresponds by definition to an energy production of $1 \mathrm{GWh}$ per year.

Energy potentials of wind power plants and biogas energy plants are not included because their potential in the study area is low in comparison with other energy sources (Müller et al. 1995, Buser et al. 1996).

All energy supply processes except deep geothermal heat, nuclear power and co-generation are operated with a renewable primary energy input. Geothermal heat as primary energy source is in principle not renewable. The Earth has been continuously cooling down since its existence. Nevertheless, geothermal heat will be available for some more billions of years and can therefore be considered as unlimited in human periods. Nuclear power and co-generation are operated with imported nonrenewable energy sources.

The energy supply processes produce energy for the process of energy industry (energy supply flows). They receive energy for manufacturing, installation and maintenance (demand flows). For better visibility Fig. 1 shows only a representation of these flows and not all energy demand and supply flows for each energy supply process.

The energy industry distributes energy to the different users, represented by the process of consumption. The two import flows from the global hinterland cover possible

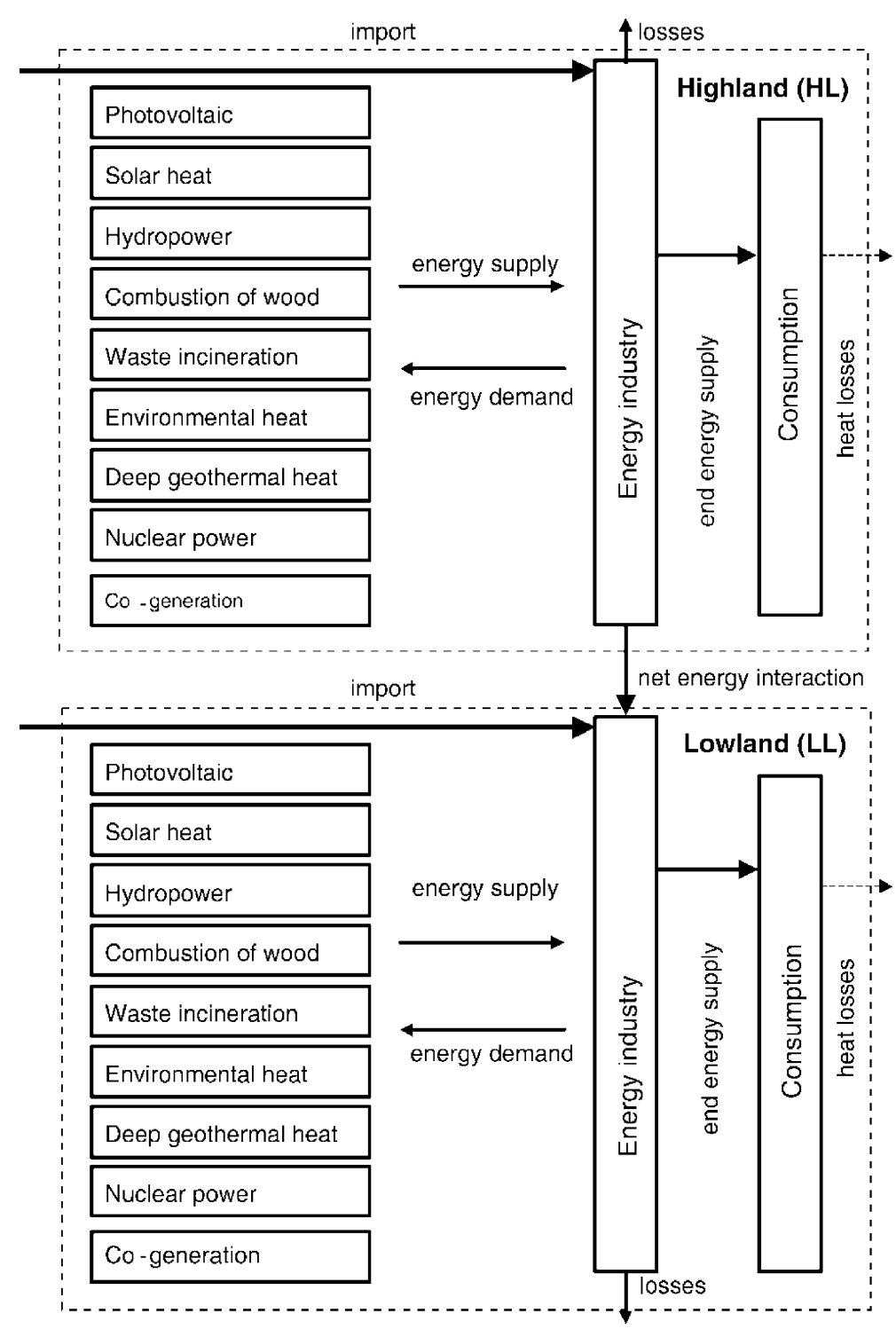

Fig. 1. Two-region system for the dynamic energy model. The arrow "energy supply" represents the energy flow from all nine supply processes. The same holds for the arrow "energy demand". The upper subsystem represents the highland (HL), the lower subsystem represents the lowland (LL) 
net energy demands of the system. The two subsystems are linked with the flux "net energy interaction". Although the system presented could treat seasonal aspects, those are not considered here, as we focus on the main questions with a long-term character.

\section{Mathematical description}

The system in Fig. 1 contains nine independent energy supply processes per region, each representing a specific energy form. Since the treatment herein of all the energy supply processes in both regions are mathematically equivalent, the procedure is illustrated for only one supply process, namely photovoltaic.

For purpose of the model, the photovoltaic energy supply process can be described by the following variables (Fig. 2):

$M(t): \quad$ stock of installed photovoltaic units $\left(\mathrm{m}^{2}\right)$ at time $t$ $I(t): \quad$ amount of installed photovoltaic units $\left(\mathrm{m}^{2}\right)$ per year

$O(t): \quad$ amount of dismantled photovoltaic units $\left(\mathrm{m}^{2}\right)$ per year

$E_{\mathrm{I}}(t): \quad$ amount of energy for construction, installation $\left(\mathrm{kWh} / \mathrm{m}^{2}\right)$, maintenance and operation per photovoltaic unit and year $\left(\mathrm{kWh} / \mathrm{m}^{2} /\right.$ year $)$

$E_{\mathrm{O}}(t): \quad$ amount of produced energy per installed unit and year $\left(\mathrm{kWh} / \mathrm{m}^{2} /\right.$ year $)$

Of course, a complete description of all details of the material and energy household of photovoltaic energy systems would require many more variables. The reason is that innumerable processes and materials are involved. However, in the sense of a first approximation the first three variables are simple indicators for the material household. Similarly, variable 4 and 5 are indicators for the energy household.

The system behaviour is mathematically described by the system of equations consisting of a balance equation (i) and model equations (ii-v):

(i) Balance equation:

$\dot{M}(t)=I(t)-O(t)$

$\dot{M}(t)$ is the derivative of $M(t)$ with respect to time.

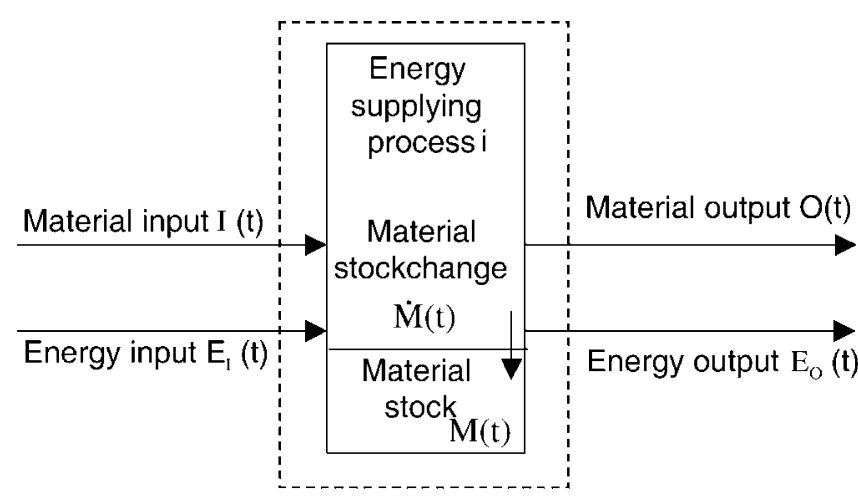

Fig. 2. The photovoltaic energy supply process with its complete set of variables as an example of all energy supply processes in both regions (ii) Implementation of photovoltaic units as a function of time: $P_{1}(t)$

$M(t)=P_{1}(t)$

$P_{1}(t)$ is a parameter function describing the assumed implementation of photovoltaic units as a function of time. To find an appropriate function $P_{1}(t)$ is a task of the calibration procedure. Based on the experience that most growth patterns of industrial products are sigmoidal or logistic, for $P_{1}$ a logistic growth function has been assumed (Fischer and Fry1970):

$P_{1}(t)=p_{1,1}+\frac{p_{1,2}}{1+\mathrm{e}^{-p_{1,3}\left(t-p_{1,4}\right)}}$

The parameters $p_{1,1}, \ldots ., p_{1,4}$ are simply related to the characteristics of the growth pattern, namely the starting and saturation value, maximum growth rate and the turning point (point of maximum growth rate) respectively (see Fig. 4 and Hug 2002).

(iii) Residence time distribution: $k\left(t, t^{\prime}\right)$

A very general formulation for the input-output relation is:

$O(t)=\int_{0}^{t} k\left(t, t^{\prime}\right) I\left(t^{\prime}\right) d t^{\prime}$

where $k\left(t, t^{\prime}\right)$ is the transfer function or residence time distribution of photovoltaic units produced at time $t^{\prime}$.A residence time distribution function $k\left(t, t^{\prime}\right)$ which has been successfully used in previous work is the two-parameter Gauss function:

$P_{2}\left(t, t^{\prime}\right)=k\left(t, t^{\prime}\right)=\frac{1}{N_{O}} \mathrm{e}^{-\frac{\left(t-t^{\prime}-\tau\right)^{2}}{2 \sigma^{2}}}$

$\tau: \quad$ average residence time of a photovoltaic unit

$\sigma: \quad$ standard deviation of $\tau$

$N_{\mathrm{O}}$ : :normalisation factor

For a more detailed description see Baccini and Bader (1996) and Zeltner et al. (1999).

(iv) Energy demand for production, maintenance and operation of the photovoltaic energy supply process per year: $E_{\mathrm{I}}(t)$

$E_{I}(t)=E_{\text {inst }}(t)+E_{\text {main }}(t)+E_{\text {oper }}(t)$

(v) Energy produced by the photovoltaic energy supply process per year: $E_{\mathrm{o}}(t)$

$E_{O}(t)=P_{6}(t) M(t)$

$P_{6}(t): \quad$ Specific energy produced per photovoltaic unit and year

The six parameter functions $P_{1}(t), \ldots, P_{6}(t)$ are the characteristic quantities determining the behaviour of all the energy supply processes. The parameter functions $P_{2}(t), \ldots, P_{6}(t)$ are "technical functions" representing the 


$$
\begin{array}{ll}
E_{\text {inst }}(t)=P_{3}(t) \cdot I(t) & P_{3}(t): \text { specific energy demand for installation and dismantling of a photovoltaic unit } \\
E_{\text {main }}(t)=P_{4}(t) \cdot M(t) & P_{4}(t): \text { specific energy demand for the maintenance of a photovoltaic unit per year } \\
E_{\text {oper }}(t)=P_{5}(t) \cdot M(t) & P_{5}(t): \text { specific energy demand for the operation of a photovoltaic unit per year }
\end{array}
$$

state of the art of the energy systems. The implementation characteristic $P_{1}(t)$ on the other hand reflects the political and socio-economic intention and is discussed for the different energy supply systems in the calibration section. The equations above for $E_{\text {main }}(t), E_{\text {oper }}(t)$ and $E_{\mathrm{O}}(t)$ are approximations for the case of constant parameter functions $P_{4}, P_{5}$ and $P_{6}$. If $P_{4}, P_{5}$ or $P_{6}$ are not constant as functions of time, Eqs. (6) and (7) have to be generalised. For details see Hug (2002).

All other energy supply processes are mathematically described in similar ways, but of course with different parameter functions.

The regional energy industry (see Fig. 1 and Fig. 3) as the managing and distribution process of the region gets its energy from the energy supply processes and if necessary also from the neighbouring region and from imports. It supports the regional consumption, the supply processes and if possible also the neighbouring region or energy exports to the "hinterland". This strategy has been formulated mathematically, describing the energy industry by a set of system equations.

The different energy supply processes produce electricity and heat energy, depending on their characteristics (see Table 2).

Since we were interested in both electricity and total energy, electricity flows and total energy flows of the system of Fig. 1 have been considered separately.

The overall system of Fig. 1, as described above, results in a total of 234 variables. The system equations form a system of 234 sparsely coupled integro-differential equations. They contain 132 parameter functions described by 248 single parameter values, which are defined by the calibration procedure and the scenario conditions,

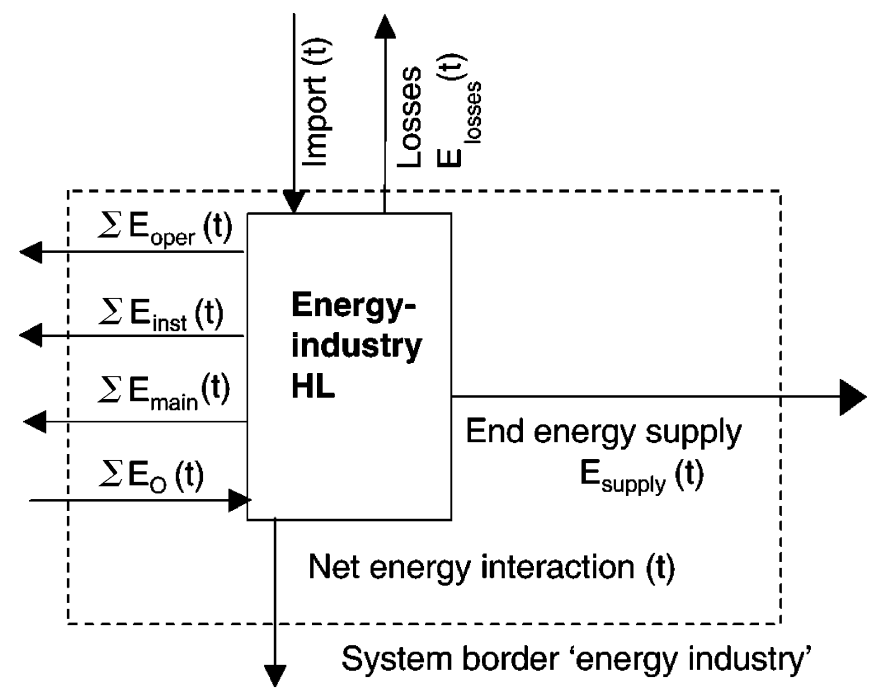

Fig. 3. Energy industry as a regional energy distribution process, illustrated for the highland (HL) respectively (see below). The initial conditions for the variables correspond to the status quo. If all parameters and the initial values are fixed, the variables as a function of time can be calculated by solving the system equations. To solve these system equations numerically, they have been implemented in the computer simulation program SIMBOX (Baccini and Bader 1996). All calculations were performed on a Pentium III PC $(1,000 \mathrm{MHz})$.

\section{Calibration of the model}

Calibration means finding the most adequate parameter functions $P_{1}(t), \ldots, P_{6}(t)$ to describe the available data. Of course this is in general not uniquely possible and not free of subjective assumptions (see also Zeltner et al. 1999). However, the selected parameter functions should be as simple as possible and of course represent the empirical data of the past. The subjective assumptions will be explained.

Figure 4 shows typologically the chosen parameter functions $P_{1}(t)$. These implementation functions for the different supply processes reflect the experience with growth patterns of industrial products. In principle all these follow more or less a logistic or sigmoidal growth curve (Fischer and Fry 1970). Strictly speaking, the implementation functions are all logistic step-functions, each step representing a new power plant brought into operation. For energy supply processes with large units, the steps are bigger and for processes with smaller units the steps are practically invisible (see Fig. 4). Figure 4a illustrates the assumed logistic implementation for photovoltaic energy, solar heat, combustion of wood and environmental heat. The corresponding function is given in Eq. (3). Figure $4 \mathrm{~b}$ shows the implementation for hydropower and waste incineration. Because of ecological and economic boundary conditions it is assumed that there is no significant future increase in hydropower and energy production from waste incineration. The mathematical description for the energy supply processes of nuclear power (c) and co-generation (e) are similar to

Table 2. Electricity output $E_{\mathrm{O}, \mathrm{el}}$ in percent of the total energy output $E_{\mathrm{O}}$ for the different energy supplying processes

Energy supplying process Electricity output as a percentage of the total

Photovoltaic energy output (\%)

Solar heat

Hydropower

Combustion of wood

Waste incineration

Environmental heat

Deep geothermal heat

Nuclear power

Co-generation 


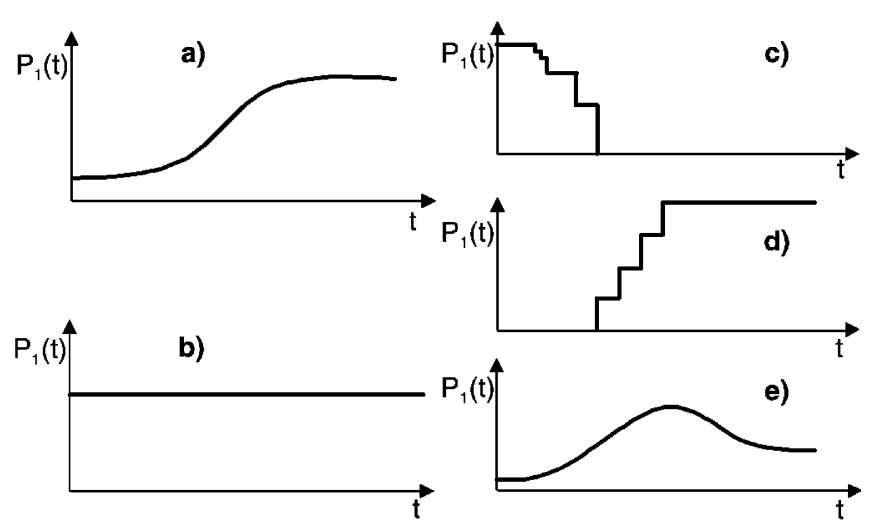

Fig. 4a-e. Typological illustration of the implementation functions $P_{1}(t)$ used. a For photovoltaic energy, solar heat, combustion of wood and environmental heat a logistic implementation function is assumed. b Hydropower and waste incineration stays constant as a function of time. c Nuclear power will be scaled down step by step while $\mathbf{d}$ deep geothermal heat increases stepwise, each step representing one plant. e Co-generation is used to prevent an energy gap after stopping nuclear power

those in Real (1998). Co-generation is used to prevent an energy gap after scaling down nuclear power step by step. The latter measure is based on political guidelines. It is assumed that $50 \%$ of the heat produced by co-generation can be used while the heat produced by nuclear power is not significantly used (this represents the current situation in Switzerland for nuclear power). The energy supply process of deep geothermal heat is finally described by a multistep function (d) due to an implementation with few single power plants.

For the parameter function $P_{2}\left(t, t^{\prime}\right)$ for photovoltaic energy, a Gaussian residence time distribution has been chosen (Eq. 5) as already discussed above. This

residence time distribution is a good approach for life cycle modelling of any technical system. Therefore, the parameter function presented in Eq. (5) is used for all energy supply processes. The parameter function $P_{3}(t), P_{4}(t), P_{5}(t)$ and $P_{6}(t)$ represent specific energy quantities. Of course, in reality, these specific energies will improve in the future. However, in the sense of a conservative first approximation they have been chosen as constant in function of time, representing the present state of technical development.

One of the goals of this study is to discuss technically feasible scenarios. Therefore, the parameter values have been chosen moderately. The most important parameter values for all energy supply processes are listed in Table 3. The photovoltaic potential is taken from Real (1998) and represents the favourable roof areas for photovoltaic energy production in the existing Swiss settlements $\left(20 \mathrm{~m}^{2}\right.$ per inhabitant and $126 \mathrm{~km}^{2}$ for Switzerland). The target value for solar heat implementation corresponds to a $1.5 \mathrm{~m}^{2}$ collector area per inhabitant. Combustion of wood will be increased to a steady state use of the regional forests. For environmental heat there are no potential data available. Therefore, it is assumed that the current use of environmental heat can be increased fivefold. For deep geothermal heat it is assumed that seven single plants will be installed, each with a power potential of a projected plant in Switzerland (http://www.dhm.ch/welcome2.html).
Nuclear power production will be scaled down after reaching the lifetime of the power plants (40 years). For further data see also (Hug 2002).

\section{Data sources}

The amount of renewable energy in operation at present is according to BEW (2000) and SEV/VSE (1996). There are only a few data available about the energy demand for production, installation, dismantling and maintenance of the energy supply processes. Principally, all data concerning the mentioned aspects are according to Frischknecht et al. (1994). Because waste incineration, deep geothermal heat, nuclear power and co-generation are based on a Carnot process, they are modelled in a similar way based on data from Real (1998) and Frischknecht et al. (1994). Data for hydropower were found in SEV/VSE (1996), VSE (1995) and Bär (1979). The current use of energy from waste incineration can be estimated according to BUWAL (1996). Rybach (1992) presents basic information about the geothermal heat potential in the Swiss lowlands while the necessary data for photovoltaic energy can be found in Real (1998).

\section{Scenarios}

The use of scenarios makes it possible to study the system behaviour as a function of time for chosen conditions. The development of the energy consumption as a function of time and the implementation time of the new energy systems turned out to be the key parameters to discuss the main questions. Therefore, these two parameters will be varied in three scenarios.

\section{Scenario (a): constant consumption-moderate implementation}

For the next 100 years it is assumed that the total energy and electricity consumption remains constant. The implementation of the new energy systems proceeds moderately. The corresponding implementation times are shown in Table 3.

\section{Scenario (b): $(1+\alpha)-k W$ consumption-moderate implementation}

The level of energy consumption per person has been discussed intensively in the last 10 years. A convenient unit to measure the energy consumption is $\mathrm{kW}$ per person. $1 \mathrm{~kW}$ per person corresponds to $8,760 \mathrm{kWh}$ per person and year. At an international conference, the so called "trilemma symposium", held in Japan 1996, the notion of a " $(1+\alpha)-\mathrm{kW}$ society" has been introduced to characterise a society which uses $(1+\alpha) \mathrm{kW}$ on average per person (Dürr 1996 and related work). At present Switzerland corresponds to a $6-\mathrm{kW}$ society. Imboden and Baccini (1996) proposed for Switzerland the 2-kW society, i.e. $\alpha=1$ for the future.

Therefore, in this scenario it is assumed that within the next 60 years the total primary energy consumption decreases in a logistic way from the level of $6 \mathrm{~kW}$ to $2 \mathrm{~kW}$ per person. Concerning electricity, it is assumed that the share of the total energy consumption of $22 \%$ at present increases logistically to about $33 \%$. Implementation times are the same as in scenario (a). 
Table 3. Parameter values for calibration of the energy supplying processes. For further data see also in Hug (2002)

\begin{tabular}{|c|c|c|c|c|c|c|c|c|c|}
\hline $\begin{array}{l}\text { Energy } \\
\text { supplying } \\
\text { process }\end{array}$ & $\begin{array}{l}\text { Installed units } \\
\text { for status } \\
\text { quo } 2000, M(t)\end{array}$ & $\begin{array}{l}\text { Installed units } \\
\text { for target } \\
\text { status }\end{array}$ & $\begin{array}{l}\text { Implementation } \\
\text { time, } \\
\text { (scenario } 1+2) \text {, } \\
1 / p_{1,3}\end{array}$ & $\begin{array}{l}\text { Average } \\
\text { assumed } \\
\text { residence } \\
\text { time, } p_{2,1} \\
\end{array}$ & $\begin{array}{l}\text { Assumed } \\
\text { standard } \\
\text { deviation, } \\
p_{2,2} \\
\end{array}$ & $\begin{array}{l}\text { Specific energy } \\
\text { production } \\
P_{6}(t) \\
\text { per unit } \\
\end{array}$ & $\begin{array}{l}\text { Specific energy } \\
\text { demand for } \\
\text { production, } P_{3}(t)\end{array}$ & $\begin{array}{l}\text { Specific energy } \\
\text { demand for } \\
\text { maintenance, } P_{4}(t)\end{array}$ & $\begin{array}{l}\text { Specific } \\
\text { energy } \\
\text { demand for } \\
\text { operation, } P_{5}(t) \\
\end{array}$ \\
\hline Photovoltaic & $0.072 \mathrm{~km}^{2}$ HL: $25 \%$ & $126 \mathrm{~km}^{2} \mathrm{HL}: 30 \%$ & 60 years & 30 years & 10 years & a & & $\approx 0 \mathrm{kWh} /$ year & $0 \mathrm{kWh} /$ year $/ \mathrm{m}^{2}$ \\
\hline Solar heat & $0.274 \mathrm{~km}^{2}$ HL: $25 \%$ & $10.8 \mathrm{~km}^{2}$ HL: $17 \%$ & 50 years & 20 years & 7 years & c & d & & $0 \mathrm{kWh} /$ year $/ \mathrm{m}^{2}$ \\
\hline Hydropower & $\begin{array}{l}\text { 34'100 GWh/year } \\
\text { HL: } 75 \%\end{array}$ & $\begin{array}{l}34,100 \text { GWh/year } \\
\text { HL: } 75 \%\end{array}$ & - & 150 years & 20 years & $1 \mathrm{GWh} / \mathrm{GWh}$ & $0.3 \mathrm{GWh} / \mathrm{GWh} /$ year & $\begin{array}{l}\approx 0 \mathrm{GWh} / \text { year/ } \\
\text { GWh/year }\end{array}$ & $\begin{array}{c}0 \text { GWh/year/ } \\
\text { GWh/year }\end{array}$ \\
\hline $\begin{array}{l}\text { Combustion } \\
\text { of wood }\end{array}$ & $\begin{array}{l}\text { 3’390 GWh/year } \\
\text { HL: } 38 \%\end{array}$ & $\begin{array}{l}8,800 \mathrm{GWh} / \text { year } \\
\text { HL: } 66 \%\end{array}$ & 30 years & 30 years & 10 years & $1 \mathrm{GWh} / \mathrm{GWh}$ & 2.6 GWh/GWh/year & $\begin{array}{l}0.02 \mathrm{GWh} / \text { year/ } \\
\text { GWh/year }\end{array}$ & $\begin{array}{l}0 \text { GWh/year/ } \\
\text { GWh/year }\end{array}$ \\
\hline $\begin{array}{l}\text { Waste } \\
\text { incineration }\end{array}$ & $\begin{array}{l}\text { 9'330 GWh/year } \\
\text { HL: } 25 \%\end{array}$ & $\begin{array}{l}\text { 9,330 GWh/year } \\
\text { HL: } 25 \%\end{array}$ & - & 40 years & 10 years & $1 \mathrm{GWh} / \mathrm{GWh}$ & 4 GWh/GWh/year & $\begin{array}{l}0.063 \mathrm{GWh} / \text { year/ } \\
\mathrm{GWh} / \text { year }\end{array}$ & $\begin{array}{c}0 \text { GWh/year/ } \\
\text { GWh/year }\end{array}$ \\
\hline $\begin{array}{l}\text { Environmental } \\
\text { heat }\end{array}$ & $\begin{array}{l}\text { 1'910 GWh/year } \\
\text { HL: } 35 \%\end{array}$ & $\begin{array}{l}\text { 9,570 GWh/year } \\
\text { HL: } 35 \%\end{array}$ & 50 years & 25 years & 7 years & $1 \mathrm{GWh} / \mathrm{GWh}$ & $2.5 \mathrm{GWh} / \mathrm{GWh} /$ year & $\begin{array}{l}0.3 \mathrm{GWh} / \text { year/ } \\
\text { GWh/year }\end{array}$ & $\begin{array}{l}0 \text { GWh/year/ } \\
\text { GWh/year }\end{array}$ \\
\hline $\begin{array}{l}\text { Deep geo- } \\
\text { thermal } \\
\text { heat }\end{array}$ & $0 \mathrm{GWh} /$ year & $2240^{\mathrm{f}} \mathrm{GWh} /$ year & Gradually $^{f}$ & 40 years & 10 years & $1 \mathrm{GWh} / \mathrm{GWh}$ & 3.6 GWh/GWh/year & $\begin{array}{l}0.056 \mathrm{GWh} / \text { year/ } \\
\text { GWh/year }\end{array}$ & $\begin{array}{c}0 \mathrm{GWh} / \text { year/ } \\
\text { GWh/year }\end{array}$ \\
\hline $\begin{array}{l}\text { Nuclear power } \\
\text { (electric+ } \\
\text { thermic, } \\
\text { only LL) }\end{array}$ & 67’850 GWh/year & $0 \mathrm{GWh} /$ year & Gradually ${ }^{\mathrm{g}}$ & 40 years & 10 years & $1 \mathrm{GWh} / \mathrm{GWh}$ & $0.08 \mathrm{GWh} / \mathrm{GWh} /$ year & $\begin{array}{l}0.056 \mathrm{GWh} / \text { year/ } \\
\text { GWh/year }\end{array}$ & $\begin{array}{l}1 \mathrm{GWh} / \text { year/ } \\
\text { GWh/year }\end{array}$ \\
\hline Co-generation & ${ }^{\mathrm{h}}$ HL: $25 \%$ & ${ }^{\mathrm{h}}$ HL: $25 \%$ & $\mathrm{~h}$ & 40 years & 15 years & $1 \mathrm{GWh} / \mathrm{GWh}$ & $0.08 \mathrm{GWh} / \mathrm{GWh} /$ year & $\begin{array}{l}0.056 \mathrm{GWh} / \text { year/ } \\
\text { GWh/year }\end{array}$ & $\begin{array}{l}1 \mathrm{GWh} / \text { year/ } \\
\text { GWh/year }\end{array}$ \\
\hline
\end{tabular}

${ }^{\mathrm{a} D}$ Different per region: For HL $150 \mathrm{kWh} / \mathrm{year} / \mathrm{m}^{2}$, for LL $115 \mathrm{kWh} /$ year $/ \mathrm{m}^{2}$

b Installation different per region: For HL $1035 \mathrm{kWh} / \mathrm{m}^{2}$, for LL $794 \mathrm{kWh} / \mathrm{m}^{2}$

${ }^{c}$ Different per region: For HL $500 \mathrm{kWh} /$ year $/ \mathrm{m}^{2}$, for LL $300 \mathrm{kWh} /$ year $/ \mathrm{m}^{2}$

${ }^{\mathrm{d}}$ Installation different per region: For HL $1320 \mathrm{kWh} / \mathrm{m}^{2}$, for LL $800 \mathrm{kWh} / \mathrm{m}^{2}$

${ }_{\mathrm{e}}^{\mathrm{e}}$ Different per region: For HL $14 \mathrm{kWh} /$ year $/ \mathrm{m}^{2}$, for LL $8.5 \mathrm{kWh} /$ year $/ \mathrm{m}^{2}$

${ }^{\mathrm{f}}$ In HL two plants built in 2025 and 2035, in LL five plants built in 2025, 2033, 2041, 2049, 2057, all plants with $0.32 \mathrm{TWh} / \mathrm{year}$

${ }^{\mathrm{g}}$ Gradually, end of decrease 2024

${ }^{\mathrm{h}}$ See Real (1998) 
Scenario (c): constant consumption-fast implementation It is assumed that the total energy consumption stays constant while the new energy systems will be implemented in half of the implementation times assumed in scenarios (a) and (b). The share of electricity of the total energy consumption stays constant.

To compare trend extrapolation with dynamical calculations, a steady state trend analysis for 2025 is investigated with data from BEW (1996a, 1996b, 1996c, 1996d). To get an idea of the confidence interval of the simulations, an uncertainty analysis has been performed. This is based on a sensitivity analysis selecting the most sensitive parameters. These are: the feasible potential; the energy demand for production, installation, dismantling and specific production per photovoltaic unit and solar heat; the realisable potentials for hydropower, combustion of wood, waste incineration and environmental heat; the total energy and electricity consumption. For all of these parameters an uncertainty between $0 \%$ and $15 \%$ was estimated.

\section{Results}

To interpret the results, the so called degree of self sufficiency (DSS) is helpful. The DSS is defined as follows:

$$
\text { DSS }=\frac{E_{\text {prod }}^{\text {(tot) }}}{E_{\text {imp }}^{\text {(tot) }}+E_{\text {prod }}^{\text {(tot) }}}
$$

where

$E_{\text {prod }}^{\text {(tot) }}: \quad$ total energy produced by the energy supply $E_{\mathrm{imp}}^{\text {(tot) }}$ processes total imported energy from neighbouring regions and from the "hinterland"

The development of the total energy for the two regions is shown in Fig. 5. The single graphs in the first and second rows represent the net energy supply, the consumption, the imports and the DSS for the highland and lowland respectively. The two graphs in the third row show the net energy interactions between the two regions and the DSS for Switzerland. For both scenarios the net energy supply increases significantly. According to the scenario assumptions the regional consumption stays constant or decreases from a $6-\mathrm{kW}$ to a $2-\mathrm{kW}$ society. As a consequence there is a slight or strong decrease in the net energy imported from the global hinterland in both regions depending on the scenario. For a $2-\mathrm{kW}$ society the HL could become self-sufficient for energy in 2030. With a further increase of the regional energy supply, the HL could then start to export net energy to the LL. This is shown by the net energy interaction as a function of time. Therefore, for a $2-\mathrm{kW}$ society, the DSS for Switzerland increases from $16 \%$ to $80 \%$. On the other hand with constant energy consumption, the DSS for Switzerland increases only slightly. Concerning the trend extrapolation
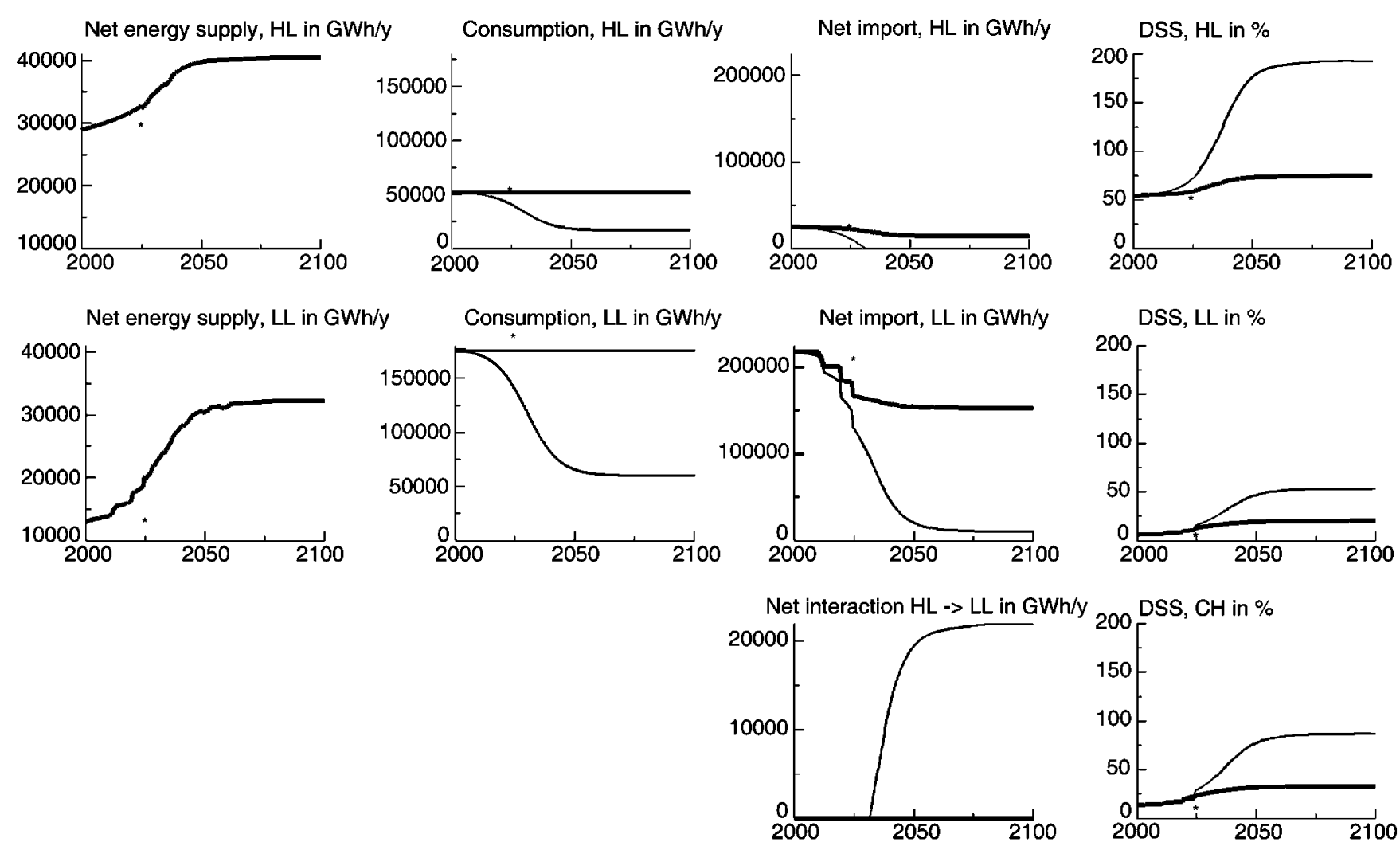

Fig. 5. Development of energy as a function of time (GWh/year) for net energy supply, consumption, regional net import and degree of self-sufficiency (DSS) for the Swiss highland (HL) and lowland (LL). The last two graphs show the interregional net energy interaction between the HL and the LL and the DSS for
Switzerland $(\mathrm{CH})$. Bold lines represent scenario (a) with constant consumption and moderate implementation. Thin lines show scenario (b) with a $2-\mathrm{kW}$ society and moderate implementation. A asterisk indicates the trend situation for 2025 
for 2025, Fig. 5 shows a clear underestimation for the net energy supply compared with the dynamical results. The trend extrapolation of the consumption is estimated to be higher than our scenario assumptions. This explains the differences in net import and DSS between extrapolation and dynamical calculations.

Figure 6 illustrates the development of the cumulative national energy supply of all energy supply processes for scenarios (a) and (b) for Switzerland. In this figure nuclear power production is included for a better understanding of the changes of the national energy system, although the primary energy for nuclear power is imported. The corresponding figure for the energy supply of scenario (c) would look similar, except that the target status is reached within half of the time. Figure 6 shows clearly that the implementation of the new energy systems could serve to replace successively nuclear power. In this, photovoltaic electricity plays the most prominent role. Note that for scenarios (a) and (b) internal energy supply for the year 2100 is in the same order of magnitude as that for the year 2000, but relies mostly on renewable energies.

At present the DSS of Switzerland for electricity is about $60 \%$. The target status of regional energy supply and consumption allows an increase of the DSS to values between $80 \%$ and $130 \%$, depending on the scenario. Therefore, the goals for a new energy household, mentioned in the Introduction, could be reached at least for electricity. These goals are replacing non-renewable with renewable resources, increasing the resource efficiency and increasing the degree of regional autonomy. For a more detailed discussion see (Hug 2002).

To discuss the necessary time for a change to a new energy household, important aspects such as material and energy demand for manufacturing as well as manpower and knowledge for installation have to be considered. The aspect of energy demand for manufacturing is shown in Fig. 7, where moderate and fast implementations are compared. It can be seen that the amplitude of the energy demand for production $E_{\text {inst }}(t)$ for a fast implementation is about twice as high as that for a slow implementation. The consequences of that demand on the national electricity and total energy household are demonstrated with the DSSs. Due to the assumption that all production energy for the new systems is electricity, a slight overshoot for a fast implementation can be seen for the DSS of electricity. For the DSS of total energy, no significant difference is visible between slow and fast implementations with the exception of an earlier increase for a fast implementation.

Photovoltaic energy shows the largest increase of all new systems (Fig. 6). Therefore the aspect of material demand and installation will be illustrated for photovoltaic energy. Figure 8 shows the material input for the photovoltaic system in square metres $\left(\mathrm{m}^{2}\right)$ per year with equal scales for the HL and the LL. Again, bold lines represent the moderate implementation while thin lines illustrate the fast implementation. For a fast implementation both regions show a strong overshoot in material demand. The peak of the implementation capacity would be around 2015. Switzerland as a whole would have to produce and install a photovoltaic area of about $10 \mathrm{~km}^{2}$ every year compared to about $0.07 \mathrm{~km}^{2}$ installed for the year 2000 . With a moderate implementation the peak capacity is half as high and occurs roughly one generation later. The consequences of this overshoot will be discussed later.

\section{Discussion of uncertainty analysis}

For the planning of the regional energy household, the uncertainties have to be considered. Most of the sensitive

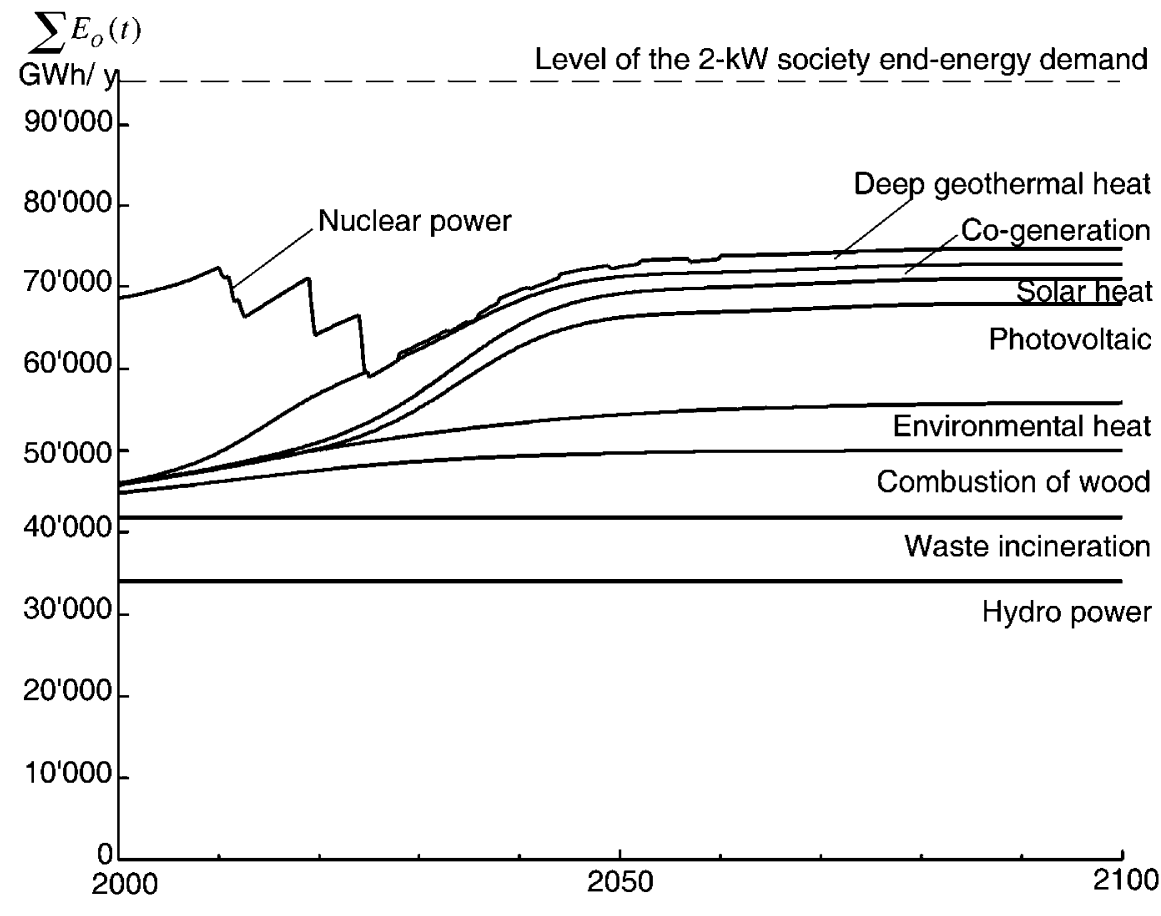

Fig. 6. Development of the cumulative energy supply for the different energy systems in Switzerland for moderate implementation times in GWh/year. The dashed line indicates the end-energy demand level of a two $2-\mathrm{kW}$ society for Switzerland 

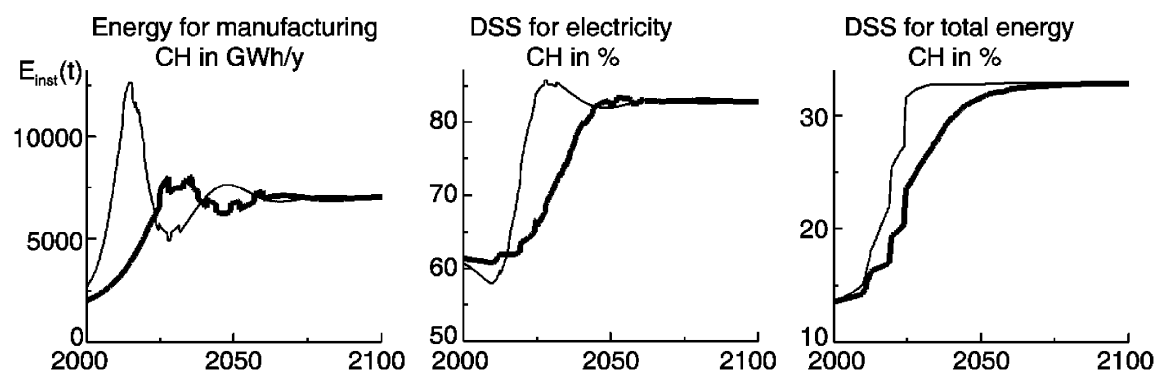

Fig. 7. Development of the energy demand for manufacturing of all new energy systems in GWh/year and degree of selfsufficiency (DSS) for total energy and electricity in Switzerland. Bold lines represent scenario (a), while thin lines represent scenario $(c)$
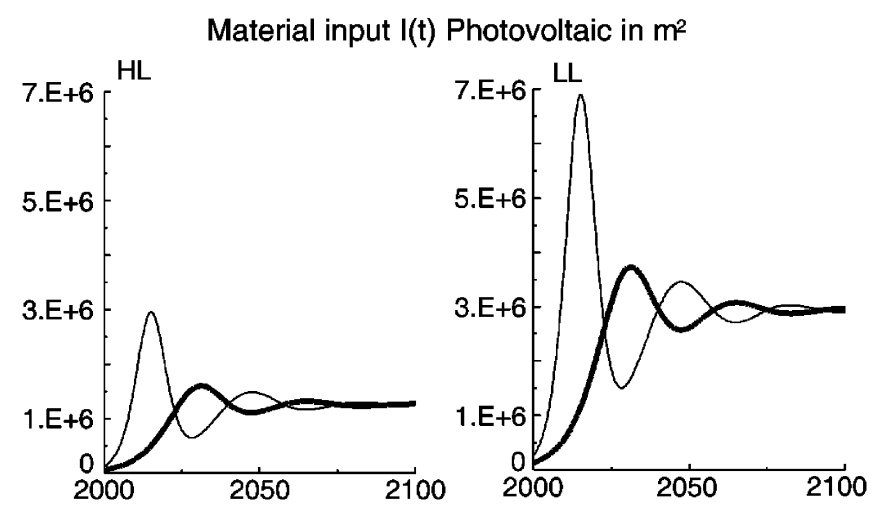

Fig. 8. Development of material input in square metres $\left(\mathrm{m}^{2}\right)$ of photovoltaic units per year for the Swiss highland (HL) and lowland (LL). Bold lines represent moderate implementation, while thin lines represent fast implementation

parameters mentioned above concern the electricity household of the regions. Therefore, the results of the uncertainty analysis will be exemplified for the electricity household for scenario (a). Figure 9 illustrates the net electricity import to the LL and the national DSS for electricity. Bold lines represent the development in scenario (a), and thin lines show the uncertainty range for one positive and one negative standard deviation. The uncertainty analysis shows for the later future (around 2050 ) significant uncertainties (up to $50 \%$ ). However, they also have to be seen in a continental European context. In this large scale the maximum standard deviation of the net electricity import to the LL represents $1.5 \%$ of today's electricity production in Europe and is, therefore, negligible. The national DSS for electricity as evaluation criteria shows an uncertainty range of around $15 \%$.

\section{Discussion and conclusions}

The dynamical simulations presented in this study allow the following important conclusions:

1. The dynamical model, presented here, uses relatively few parameters and data. However, it takes into account the whole "history" and the interactions of all parts of the system considered. By "history" we mean the "age structure" of the supply processes, which is important for their material and energy demand and their energy production respectively, as discussed above. With this dynamical model the development of the energy household has been studied for a two-region system.
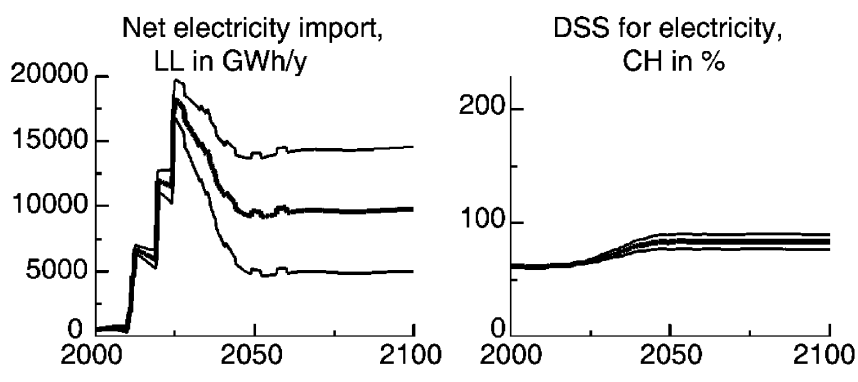

Fig. 9. Uncertainty analysis for the net electricity import in the Swiss lowland (LL) in GWh/year and the national DSS for electricity in \%. The bold lines represent scenario (a) with constant consumption and moderate implementation, while the thin lines represent the uncertainty range of one standard deviation

In particular, the so-called "transition zone" between the present state and a future target state has been discussed in detail. This is not possible with trend extrapolations, which use large data sets to extrapolate into the future without considering the interactions and the history of the system. By their very nature, such trend extrapolations can describe the future behaviour only in a shortterm way, normally a few years. This important limitation of trend analysis has been observed by many authors in different fields (Real 1998, Krämer 2000, Martens 1984, Metzler 1987).

2. To discuss possible limitations in implementation speed, the production capacity and the energy demand for manufacturing have been analysed. It has been shown (Fig. 8) that short implementation times $(\approx 30$ years) would require large production overcapacities during the implementation period. For the "renewal" period, following the implementation period, only about half of that overcapacity would be used. Production in this context includes not only the manufacturing companies, but also the installation by well trained specialists. The reduction of overcapacities has economic and socio-economic consequences which are well known from other products in economic growth markets. An up-to-date example is the computer manufacturing industry reaching saturation after a period of rapid growth.

The energy demand for manufacturing on the other hand, as shown in Fig. 7, is not a speed limiting factor for implementations. The reason is that this energy demand affects the national energy household only slightly. 
3. Based on the potentials for renewable energy and the actual population, Switzerland could reach an energy supply on a highly sustainable level (with the highlands making a large energy supply for the lowlands.) However, this would require a drastic reduction of the energy consumption per person, namely by a factor of about 3 down to a level of $\approx 2 \mathrm{kWh}$ per capita.

The question is if such a reduction is realistic, especially for the two main parts of the energy consumption: heating $(\approx 25 \%)$ and transport $(\approx 35 \%)$.

For heating such a reduction is possible using state of art of house construction. For transportation a reduction of the energy demand by a factor of 3 is technologically possible. However, the general trend indicates the opposite development.

It is clear that this relatively simple dynamical model cannot cover all aspects of an implementation of renewable energy systems on a large scale. In this study, the relevant flows and material flows in the form of the number of supply units have been considered. A generalisation to include financial aspects as costs and capital used is possible and is currently in progress (Real et al. 2003). All problems of industrial manufacturing and connection of the decentralised energy supply units to the grid etc. cannot be included. However, the model is able to indicate possible limitations of an implementation of renewable energy systems. In this sense it is a contribution to the important discussion of how to reach a more sustainable energy supply for the future. This is necessary since the world's crude oil and natural gas reserves will most probably reach a critically low level in the second half of the 21st century (OECD/ IEA 2000).

\section{References}

Baccini P, Bader H-P (1996) Regionaler Stoffhaushalt. Spektrum Akademischer Verlag, Heidelberg

Baccini P, Brunner PH (1991) Metabolism of the anthroposphere. Springer, Berlin Heidelberg New York

Bär (1979) Geographie der Schweiz. Lehrmittelverlag des Kantons Zürich, Zürich

BEW (1996a) Perspektiven der Energienachfrage des Verkehrs für die Szenarien I bis III 1990-2030. Bundesamt für Energiewirtschaft, Bern

BEW (1996b) Perspektiven der Energienachfrage der Industrie für die Szenarien I bis III 1990-2030. Bundesamt für Energiewirtschaft, Bern

BEW (1996c) Perspektiven der Energienachfrage der privaten Haushalte für die Szenarien I bis III 1990-2030. Bundesamt für Energiewirtschaft, Bern

BEW (1996d) Analyse und Bewertung des Elektrizitätsangebotes für die Szenarien I bis III 1990-2030. Bundesamt für Energiewirtschaft, Bern

BEW (2000) Schweizerische Statistik der erneuerbaren Energien. Bundesamt für Energie, Bern

Binder C, Bader H-P, Scheidegger R, Baccini P (2001) Dynamic models for managing durables using a stratified approach: the case of Tunja, Columbia. Ecol Econ 38 (2001):191207

Buser H, Kunz S, Horbaty R (1996) Windkraft und Landschaftsschutz. Bundesamt für Energiewirtschaft, Bern
BUWAL (1996) Umweltmaterialien-Abfallstatistik. Bundesamt für Umwelt, Wald und Landschaft, Bern

Dürr (1996) Promote new relation between technology and human development. Lecture Record, Trilemma Symposium, Tokyo, Japan http://criepi.denken.or.jp/trilemma/en/smp/s_idx96_2.html

Faist M (2000) Ressourceneffizienz in der Aktivität Ernähren-Akteurbezogene Stoffflussanalyse. PhD Thesis 13884, Eidgenössische Technische Hochschule, Zürich

Fischer JC, Fry RH (1970) Simple substitution model of technological change. Report 70-C-215. General Electricity Company, R+D Center, Schenectady, NY, Technical Information Series June

Frischknecht R, Hofstetter P, Knoepfel I, Dones R, Zollinger E (1994) Ökoinventare für Energiesysteme. Bundesamt für Energiewirtschaft, Bern

Hug F (2002) Ressourcenhaushalt alpiner Regionen und deren physiologische Interaktionen mit den Tiefländern im Kontext einer nachhaltigen Entwicklung. PhD Thesis 14540, Eidgenössische Technische Hochschule, Zürich

Hug F, Baccini P (2002) Physiological interactions between highland and lowland regions in the context of long-term resource management. Mt Res Dev 22(2):168-176

Imboden D, Baccini P (1996) Konzepte für eine nachhaltige Schweiz: Mit welchen Ressourcen in welchen Siedlungen auf wessen Land? In: Wehowsky S, Pieren K (eds) Nachhaltige Entwicklung oder hoher Lebensstandart? CASS-Symposium 96, Konferenz der schweizerischen wissenschaftlichen Akademien. Swiss Academy of Sciences, Bern, pp 45-82

Johnstone IM (2001a) Energy and mass flows of housing: a model and example. Building Environ 36(2001):27-41

Johnstone IM (2001b) Energy and mass flows of housing: estimating mortality. Building Environ 36(2001):43-51

Keating M (1998) Agenda für eine nachhaltige Entwicklung. Centre for Our Common Future, Geneva

Krämer W (2000) So lügt man mit Statistik. Piper, München

Martens B (1984) Differntialgleichungen und dynamsiche Systeme in den Sozialwissenschaften. Profil, München

Metzler W (1987) Dynamische Systeme in der Ökologie. Teubner, Stuttgart

Müller DB (1998) Modellierung, Simulation und Bewertung des regionalen Holzhaushaltes. Department for Resource and Waste Management. PhD Thesis 12990, Eidgenössische Technische Hochschule, Zürich

Müller D, Oehler D, Baccini P (1995) Regionale Bewirtschaftung von Biomasse. vdf, Hochschulverlag an der ETH-Zürich, Zürich

OECD/IEA (2000) World energy outlook. International Energy Agency, Paris

Real M (1998) A methodology for evaluating the metabolism in the large scale introduction of renewable energy systems. Department for Resource and Waste Management. PhD Thesis 12937, Eidgenössische Technische Hochschule, Zürich

Real M, Bader H-P, Scheidegger R (2003) Dynamic simulations on large scale implementation of renewable energies: impact on greenhouse gas emissions, financial needs and sustainability. Talk given in BUWAL 2001 (in preparation)

Redle M (1999) Kies- und Energiehaushalt urbaner Regionen in Abhängigkeit der Siedlungsentwicklung. Department for Resource and Waste Management. PhD Thesis 13108, Eidgenössische Technische Hochschule, Zürich

Rybach L (1992) Geothermal potential of the Swiss Molasse Basin. Eclogae Geologicae Helvetiae 85(3):733-744

SEV/VSE (1996) Schweizerische Gesamtenergiestatistik. Verband Schweizerischer Elektrizitätswerke in co-operation with Bundesamt für Energiewirtschaft (BEW), Bern

Truffer B, Markard J, Bratrich C, Wehrli B (2001) Green electricity from alpine hydropower plants. Mt Res Dev 21(1):19-24

VSE (1995) Grösste Kraftwerke der Schweiz. Verein Schweizerische Elektrizitätswerke, Zürich

Zeltner C, Bader H-P, Scheidegger R, Baccini P (1999) Sustainable metal management exemplified by copper in the USA. Reg Environ Change 1(1):31-46 